Jurnal IImu Fisika dan Pembelajarannya (JIFP), Vol. 2, No.2, Desember 2018, 53-61

\title{
PENGARUH PENERAPAN MODEL ARGUMENT DRIVEN INQUIRY (ADI) PADA PEMBELAJARAN IPA TERHADAP KETERAMPILAN ARGUMENTASI SISWA SMP BERDASARKAN PERBEDAAN KEMAMPUAN AKADEMIK
}

\author{
Intan Kamila Zahara ${ }^{1}$, Undang Rosidin ${ }^{1}$, Kartini Helina' dan Neni Hasnunidah ${ }^{2}$ \\ ${ }^{1}$ Program Studi Pendidikan Fisika Universitas Lampung \\ ${ }^{2}$ Program Studi Pendidikan Biologi, Universitas Lampung
}

intankamila96@gmail.com

\begin{abstract}
This study aims to determine the application of the Argument Driven Inquiry (ADI) model to the argumrntation skills of high and low academic abilities in the material and optics in SMP Negeri 13 Bandar Lampung. The sample of this study is class VIII.2 and VIII.3, each of which is 32 people. The study design was the Pretest-Posttest Control Group Design. Data collection was done by pretest and posttest using instruments of student argumentation skills that tested using Independent Sample T-Test with SPSS 21.0. Based on the results of the Independent Sample Samples T-Test Value Sig. (2-tailed) <a $(0,000<0,05)$, it can produce the highest and lowest average values in the experimental class and control class. This is needed with the average value of $\mathrm{N}$-gain in students with high academic ability in the experimental class 0.70 with the medium category and the control class 0.55 with the medium category. Then in students with low academic abilities in the experimental class 0.55 with the medium category and the control class 0.48 with the medium category. Based on the results obtained it can be concluded that the ADI learning model has a significant influence on the argumentation skills of students with high and low academic abilities.
\end{abstract}

Keywords: Argument Driven Inquiry model, Argumentation skills, Academik ability

ABSTRAK

Penelitian ini bertujuan untuk mengetahui pengaruh penerapan model Argument Driven Inquiry (ADI) terhadap keterampilan argumentasi siswa berkemampuan akademik tinggi dan rendah pada materi cahaya dan optik di SMP Negeri 13 Bandar Lampung. Sampel penelitian ini yaitu kelas VIII.2 dan VIII.3 yang masing-masing berjumlah 32 siswa. Desain penelitian yang digunakan adalah Pretest-Posttest Control Group Design. Pengumpulan data dilakukan dengan pretest dan posttest menggunakan instrumen keterampilan argumentasi siswa yang diuji menggunakan uji Independent Sample T-Test dengan SPSS 21.0 . Berdasarkan hasil dari uji Independent Sample T-Test nilai Sig. $(2$-tailed $) \leq \alpha \quad(0,000<0,05)$, maka dapat dinyatakan terdapat perbedaan rata-rata keterampilan argumentasi siswa berkemampuan akademik tinggi dan rendah pada kelas eksperimen dan kelas kontrol. Hal ini ditunjukkan dengan adanya perbedaan rata-rata $\mathrm{N}$-gain pada siswa berkemampuan akademik tinggi di kelas eksperimen 0,70 dengan kategori sedang dan kelas kontrol 0,55 dengan kategori sedang. Kemudian pada siswa berkemampuan akademik rendah di kelas eksperimen 0,55 dengan kategori sedang dan kelas kontrol 0,48 dengan kategori sedang. Berdasarkan hasil yang diperoleh tersebut dapat disimpulkan bahwa model pembelajaran $\mathrm{ADI}$ memberikan pengaruh yang signifikan terhadap keterampilan argumentasi siswa berkemampuan akademik tinggi dan rendah.

Kata kunci: Model Argument Driven Inquiry, Keterampilan Argumentasi, Kemampuan Akademik

\section{PENDAHULUAN}

Pendidikan di abad 21 menantang masyarakat berpengetahuan memiliki keterampilan learning and innovation skills (keterampilan belajar dan berinovasi) meliputi keterampilan berpikir kritis dan mengatasi masalah (critical thinking and problem solving), keterampilan komunikasi efektif (communication skills), keterampilan bekerjasama secara kolaborasi (collaboration skills), serta keterampilan kreativitas dan inovasi (creativity and innovation) (Trilling \& Fadel, 2009: 47).

Salah satu cara untuk mewujudkan keterampilan yang harus dimiliki pada abad 21 dalam dunia pendidikan adalah dengan dikembangkannya kurikulum 2013. Pada Kurikulum 2013 revisi, melatihkan keterampilan 
fisikal (hardskill) dan keterampilan mental (softskill) dilakukan dengan kegiatan 5M antara lain: Mengamati, menanya, mencoba, menganalisis dan mengkomunikasikan (Kemendikbud, 2013). Keterampilan berkomunikasi merupakan softskill yang perlu dikembangkan untuk menjawab tantangan pembelajaran sains abad 21. Salah satu kemampuan komunikasi yang memainkan peran penting pada ilmu pengetahuan adalah argumentasi ilmiah.

Argumentasi ilmiah adalah kemampuan mengemukakan ide atau gagasan yang mampu menunjukkan hubungan antara hasil pemikiran dengan bukti nyata yang ada dalam sains (Duschl et al., 2007). Kemampuan argumentasi ilmiah sangat penting dilatihkan di dalam pembelajaran IPA agar siswa memiliki nalar yang logis, pandangan yang jelas, dan penjelasan yang rasional terhadap fenomena sains yang terjadi didalam kehidupan sehari-hari berdasarkan teori/konsep sains yang relevan.

Berdasarkan hasil studi pendahuluan di 25 SMP/MTs di Bandar Lampung, kegiatan pembelajaran IPA belum mampu memfasilitasi kemampuan argumentasi siswa dimana sebanyak $46 \%$ belum mengetahui tentang keterampilan argumentasi. Permasalahan tersebut tentunya tidak terlepas dari peran guru. Masih banyak guru yang kurang memperhatikan pentingnya keterampilan argumentasi dalam pembelajaran IPA. Berdasarkan hasil wawancara dengan guru diperoleh bahwa sebesar $53 \%$ guru belum menilai keterampilan argumentasi siswa pada pembelajaran IPA. Kebanyakan guru belum menemukan model pembelajaran yang tepat untuk melatih kemampuan argumentasi siswa dalam pembelajaran IPA.

Berdasarkan permasalahan di atas, maka diperlukan suatu model pembelajaran yang tepat dalam kegiatan laboratorium dan melibatkan siswa secara aktif untuk melatih kemampuan argumentasi ilmiah. Model Argument-Driven Inquiry (ADI) dipandang dapat melatihkan keterampilan argumentasi siswa. Menurut Hasnunidah (2016), model pembelajaran ADI pada dasarnya merupakan model pembelajaran inkuiri berbasis laboratorium yang dikembangkan dengan argumentasi ilmiah untuk mendorong peserta didik bekerja dalam kelompok eksperimen sehingga dpat meningkatkan pemahaman konsep penting dan praktis dalam IPA. Keterampilan argumentasi yang dimiliki setiap siswa tidak sama. Hal ini disebabkan oleh perbedaan kemampuan akademik yang dimiliki oleh siswa. Kemampuan akademik menurut Winarni (2006) dibagi menjadi 2 yaitu kemampuan akademik tinggi dan rendah.

Berdasarkan hasil wawancara dengan guru di SMP Negeri 13 Bandar Lampung, pembelajaran IPA khususnya pada bidang Fisika sudah menggunakan kurikulum 2013. Guru sudah menerapkan model pembelajaran inkuiri dengan memanfaatkan fasilitas laboratorium, namun dalam pelaksanaannya masih kurang optimal karena pembelajaran fisika yang dilakukan selama ini kurang mengarah pada pengembangan keterampilan argumentasi siswa dan kurang memperhatikan berbedaan kemampuan akademik yang dimiliki 
siswa. Hal ini dikarenakan guru memiliki keterbatasan alokasi waktu dalam melaksanakan pembelajaran dikelas. Berkaitan dengan latar belakang tersebut, maka dilakukan penelitian yang berjudul "Pengaruh Penerapan Model Argument Driven Inquiry (ADI) pada Pembelajaran IPA Terhadap Keterampilan Argumentasi Siswa SMP Berdasarkan Kemampuan Akademik."

\section{TINJUAUAN PUSTAKA}

\section{Model Argument Driven Inquiry (ADI)}

Model ADI menurut Demircioglu \& Ucar (2015) berbeda dari model lain yang memberikan siswa kesempatan untuk mendesain penelitian mereka dan menemukan hasil penelitian mereka sendiri. Siswa juga akan terlibat banyak dalam proses argumentasi dimana mereka dapat berbagi dan mendukung ide-ide mereka. Model ini terdiri dari ulasan yang meningkatkan keterampilan berpikir kritis siswa. Model ini juga dianggap sebagai model yang efektif untuk meningkatkan komunikasi dan kemampuan menulis siswa, membangun ilmu pengetahuan siswa, dan mengajak siswa mengalami langsung proses pembentukan pengetahuan mereka.

Model ADI memiliki sintak (langkahlangkah) dalam pelaksanaan-nya. Penelitian ini menggunakan sintak ADI yang telah dikembangkan oleh Hasnunidah (2016), yaitu: (1) Identifikasi tugas; (2) Pengumpulan data; (3) Produksi argumen tentatif; (4) Sesi interaktif argumentasi; (5) Penyusunan laporan penyelidikan tertulis; (6) Review laporan; (7) Proses revisi laporan; (8) Diskusi reflektif.

\section{Keterampilan Argumentasi}

Argumentasi menurut Kuhn \& Reiser (2006) merupakan proses berpikir yang dapat dikembangkan melalui penalaran dalam diskusi kelompok. Siswa perlu memberikan bukti-bukti (data) dan teori yang akurat untuk mendukung klaim mereka terhadap suatu per-masalahan dalam berargumentasi.

Osborne et al., (2004) mengem-bangkan kerangka kerja untuk mengidentifikasi kualitas argumentasi berdasarkan model argumentasi Toulmin.

Tabel 1. Kerangka Kerja Analitik untuk Menilai Kualitas Argumentasi

\begin{tabular}{|c|l|}
\hline $\begin{array}{c}\text { Leve } \\
\text { I }\end{array}$ & \multicolumn{1}{|c|}{ Kriteria } \\
\hline 1 & $\begin{array}{l}\text { Argumentasi mengandung argumen } \\
\text { dengan satu klaim sederhana } \\
\text { melawan suatu klaim yang } \\
\text { bertentangan atau satu klaim } \\
\text { melawan klaim lainnya. }\end{array}$ \\
\hline 2 & $\begin{array}{l}\text { Argumentasi mengandung klaim } \\
\text { dengan data, penjamin atau } \\
\text { pendukung tetapi tidak mengandung } \\
\text { sanggahan }\end{array}$ \\
\hline 3 & $\begin{array}{l}\text { Argumentasi mengandung sebuah } \\
\text { rangkaian dengan data, penjamin, } \\
\text { atau pendukung serta penyanggah } \\
\text { yang lemah. }\end{array}$ \\
\hline 4 & $\begin{array}{l}\text { Argumentasi mengandung sebuah } \\
\text { rangkaian klaim dengan data, } \\
\text { penjamin, atau pendukung dengan } \\
\text { satu penyanggah yang jelas }\end{array}$ \\
\hline 5 & $\begin{array}{l}\text { Argumentasi mengandung beberapa } \\
\text { argumen dengan lebih dari satu } \\
\text { penyanggah yang jelas. }\end{array}$ \\
\hline
\end{tabular}

Osborne, et al., (2004)

\section{Kemampuan Akademik}

Kemampuan akademik merupakan kemampuan untuk berkomunikasi secara ilmiah baik secara lisan maupun tulisan dan mampu berpikir logis, kritis, sistematis, dan analitis serta memiliki kemampuan untuk mengidentifikasi dan 
merusmuskan masalah yang sedang dihadapi (Saleh, 2014).

Kemampuan akademik siswa menurut Winarni (2006) dapat dikelompokkan menjadi dua yaitu siswa berkemampuan tinggi dan rendah. Apabila siswa memiliki tingkat kemampuan akademik berbeda kemudian diberi pengajaran yang sama, maka hasil belajar (pemahaman konsep) akan berbeda-beda sesuai dengan tingkat kemampuannya, karena hasil belajar berhubungan dengan kemampuan siswa dalam mencari dan memahami materi yang dipelajari.

Pengelompokan kemampuan akademik siswa didasarkan pada nilai UAS IPA semester ganjil tahun ajaran 2017/2018, dengan acuan nilai Kriteria Ketuntasan Minimal (KKM). Nilai KKM mata pelajaran IPA di SMP Negeri 13 Bandar Lampung adalah 7,5.

Tabel 2. Kriteria Kemampuan Akademik Siswa

\begin{tabular}{|c|c|}
\hline Nilai & Kriteria \\
\hline$>75$ & Tinggi \\
\hline$\leq 75$ & Rendah \\
\hline
\end{tabular}

\section{METODE PENELITIAN}

Penelitian ini dilaksanakan di SMP Negeri 13 Bandar Lampung pada tanggal 22 Juli 2018 - 2 Agustus 2018. Jenis penelitian ini adalah kuantitatif. Populasi dalam penelitian ini adalah seluruh siswa kelas VIII semester ganjil SMP Negeri 13 Bandar Lampung tahun pelajaran 2018-2019 yang terdiri dari 10 kelas. Penelitian ini mengambil sebagian dari populasi yang akan dijadikan sampel. Teknik pengambilan sampel yang digunakan dalam penelitian ini adalah teknik random sampling. Sampel dalam penelitian ini adalah kelas VIII.2 sebagai kelas eksperimen yang diberi perlakuan model ADI $\left(X_{1}\right)$ dan kelas VIII.3 sebagai kelas kontrol yang diberi perlakuan non-ADI yaitu model inkuiri terbimbing $\left(X_{2}\right)$ pada materi cahaya dan optik. Desain penelitian ini adalah quasy experimental dengan pretest-posttest control group design.

Tabel 3. Denah Perlakuan

\begin{tabular}{|c|c|c|c|}
\hline Kelas & Pretes & Perlakuan & Postes \\
\hline VIII-2 & O1 & X1 & O2 \\
\hline VIII-3 & O3 & X2 & O4 \\
\hline
\end{tabular}

$$
\begin{aligned}
& \text { Keterangan: } \\
& \text { O1 = Pretes kelas eksperimen } \\
& \mathrm{O} 2 \text { = Postes kelas eksperimen } \\
& \mathrm{O} 3=\text { Pretes kelas kontrol } \\
& \text { O4 = Postes kelas eksperimen }
\end{aligned}
$$

Instrumen dalam penelitian ini berbentuk tes essay dengan rubrik penilaian yang dikembangkan oleh Osborne, et al (2004) untuk mengukur peningkatan keterampilan argumentasi siswa.

Analisis instrumen dilakukan dengan uji validitas menggunakan program aplikasi SPSS 21.0 for windows. Persamaan yang digunakan untuk menguji validitas instrumen dalam Arikunto (2012:87) yaitu rumus korelasi product moment, yaitu :

$$
r_{X Y}=\frac{N \sum X Y-\left(\sum X\right)\left(\sum Y\right)}{\sqrt{\left\{N \sum X^{2}-\left(\sum X\right)^{2}\right\}\left\{N \sum Y^{2}-\left(\sum Y\right)^{2}\right\}}}
$$

Keterangan:

$$
\begin{array}{ll}
r_{X Y}= & \text { Koefisien korelasi yang menyatakan } \\
& \text { validitas } \\
X & =\text { Skor butir soal } \\
Y & =\text { Skor total } \\
n & =\text { Jumlah Sampel }
\end{array}
$$


Kemudian dilakukan uji reliabilitas terhadap instrumen yang valid. Rumus yang digunakan untuk mencari koefisien reliabilitas bentuk uraian menurut (Arikunto, 2012: 111) dikenal dengan rumus alpha seperti berikut.

$$
r_{11}=\left(\frac{n}{n-1}\right)\left(1-\frac{\sum \sigma_{1}^{2}}{\sigma_{t}^{2}}\right)
$$

Keterangan:

$\mathrm{r}_{11}=$ reliabilitas yang dicari

$\sum \sigma_{i}^{2}=$ jumlah varians skor setiap item

$\sigma_{\mathrm{t}}^{2}=$ varians skor total

$\mathrm{n} \quad$ = banyaknya butir

Data keterampilan argumentasi siswa yang diperoleh dari hasil pretest dan posttest kemudian dianalisis dengan melakukan (1) Uji normalitas,(2) Uji homogenitas (3) Uji N-Gain dengan persamaan berikut:

(4) Independent Sample T-Test menggunakan software SPSS 21.0 for windows. Cara menguji hipotesis ini, yaitu membandingkan nilai Sig.(2-tailed) pada uji- T dengan nilai $\alpha(0,05)$ dengan kriteria uji sebagai berikut:

1) Jika nilai Sig.(2-tailed) $\leq a(0,05)$, maka tolak $H_{0}$.

2) Jika nilai Sig.(2-tailed) $>$ a $(0,05)$, maka terima $H_{0}$

\section{HASIL DAN PEMBAHASAN}

Data kuantitatif pada penelitian ini didapatkan dari hasil pretest yang diadakan sebelum melaksanakan pembelajarandan posttest yang diadakan setelah melakukan pembelajaran. Rata-rata hasil pretest dan posttest siswa dapat dilihat pada Tabel 4.
Tabel 4. Data Rata-Rata Hasil Pretest dan Posttest Siswa

\begin{tabular}{|l|l|l|l|l|l|}
\hline $\begin{array}{c}\text { Paramet } \\
\text {-er }\end{array}$ & $\begin{array}{c}\text { Kemampu } \\
\text {-an } \\
\text { akademik }\end{array}$ & $\mathbf{O}_{\mathbf{1}}$ & $\mathbf{O}_{\mathbf{3}}$ & $\mathbf{O}_{\mathbf{2}}$ & $\mathbf{O}_{\mathbf{4}}$ \\
\hline \multirow{2}{*}{$\begin{array}{l}\text { Nilai } \\
\text { terendah }\end{array}$} & Tinggi & 20 & 20 & 65 & 55 \\
\cline { 2 - 6 } & Rendah & 20 & 20 & 55 & 50 \\
\hline $\begin{array}{l}\text { Nilai } \\
\text { tertinggi }\end{array}$ & Tinggi & 50 & 45 & 90 & 80 \\
\cline { 2 - 6 } & Rendah & 50 & 45 & 80 & 75 \\
\hline \multirow{2}{*}{$\begin{array}{l}\text { Rata-rata } \\
\text { nilai }\end{array}$} & Tinggi & 34 & 33 & 80 & 70 \\
\cline { 2 - 7 } & Rendah & 33 & 30 & 69 & 64 \\
\hline
\end{tabular}

Dari tabel dapat dilihat bahwa nilai posttest siswa mengalami peningkatan. Nilai posttest siswa berkemampuan akademik tinggi maupun rendah pada kelas eksperimen lebih tinggi dibandingkan dengan kelas kontrol. Adanya pengaruh penerapan model ADI terhadap kemampuan argumentasi siswa tersebut karena model ADI memfasilitasi siswa untuk berargumentasi melalui fase argumen tentatif dan sesi argumentasi, sehingga siswa mampu mengembangkan kebiasaan berpikir ilmiah. Hasil penelitian ini sesuai dengan kemanfaatan model ADI menurut Sampson et al., (2009) yang menyatakan bahwa model ADI membantu pengembangan literasi sains dan membantu siswa dalam mengembangkan kebiasaan berpikir ilmiah.

Peningkatan keterampilan argumentasi siswa dapat dilihat dari selisih antara hasil tes sebelum diberikan perlakuan dengan hasil tes setelah diberi perlakuan menggunakan model ADI. Rata-rata $\mathrm{N}$-Gain keterampilan argumentasi siswa dapat dilihat pada Tabel 5. 
Tabel 5. Perolehan N-Gain Keterampilan Argumentasi Siswa

\begin{tabular}{|l|c|c|c|c|}
\hline \multirow{2}{*}{$\begin{array}{c}\text { Perolehan } \\
\text { Skor }\end{array}$} & \multicolumn{2}{|c|}{ Kelas Eksperimen } & \multicolumn{2}{c|}{ Kelas Kontrol } \\
\cline { 2 - 5 } & $\begin{array}{c}\text { Akade- } \\
\text { mik } \\
\text { Tinggi }\end{array}$ & $\begin{array}{c}\text { Akade- } \\
\text { mik } \\
\text { Rendah }\end{array}$ & $\begin{array}{c}\text { Akade } \\
\text { mik } \\
\text { Tinggi }\end{array}$ & $\begin{array}{c}\text { Akade- } \\
\text { mik } \\
\text { Rendah }\end{array}$ \\
\hline $\begin{array}{l}\text { Gain } \\
\text { Terendah }\end{array}$ & 40 & 25 & 20 & 25 \\
\hline $\begin{array}{l}\text { Gain } \\
\text { Tertinggi }\end{array}$ & 55 & 45 & 55 & 40 \\
\hline $\begin{array}{l}\text { Rata-rata } \\
\text { Gain }\end{array}$ & 45 & 36,8 & 37 & 34 \\
\hline $\begin{array}{l}\text { Kenaikan } \\
\text { Skor rata- } \\
\text { rata }\end{array}$ & $45 \%$ & $37 \%$ & $37 \%$ & $34 \%$ \\
\hline $\begin{array}{l}\text { Rata-rata } N- \\
\text { Gain }\end{array}$ & 0,70 & 0,55 & 0,55 & 0,48 \\
\hline Kategori & Sedang & Sedang & Sedang & Sedang \\
\hline
\end{tabular}

Dari Tabel 5 dapat diketahui bahwa pada siswa berkemampuan akademik tingi maupun rendah, rata-rata $N$-Gain pada kelas eksperimen lebih besar dari rata-rata $N$-Gain kelas kontrol, kemudian rata-rata $N$-Gain siswa berkemampuan akademik tinggi lebih besar dibandingkan dengan siswa berkemampuan akademik rendah pada kelas eksperimen maupun kontrol. Artinya, model pembelajaran ADI lebih efektif untuk meningkatkan keterampilan argumentasi siswa dibandingkan model pembelajaran inkuiri terbimbing, hal ini disebabkan karena model ADI membiasakan siswa berdiskusi dalam kelompok, melakukan produksi argumen tentatif dimana pada tahap ini siswa dituntun untuk membuat argumentasi pada skema argumentasi yang telah disediakan, kemudian siswa akan terlibat pada sesi interaktif argumentasi dimana pada tahap ini siswa dituntun untuk mengkomunikasikan argumentasinya, mengkritik argumen siswa lain dan memperbaiki penjelasan argumen siswa lain, kemudian siswa menyusun laporan penyelidikan sesuai LKPD ADI yang telah diberikan. Sedangkan pada model inkuiri terbimbing, setelah mengumpulkan data dan menguji hipotesisnya dengan melakukan penelitian, siswa langsung dituntun untuk merumuskan kesimpulan, dan tidak ada sesi argumentasi pada tahap pembelajaran ikuiri terbimbing

Peningkatan keterampilan argumentasi siswa berkemampuan akademik tinggi lebih besar daripada siswa berkemampuan akademik rendah. Menurut Winarni (2006) apabila siswa dengan kemampuan akademik berbeda diberi pembelajaran yang sama, maka hasil belajar berupa pemahaman konsep (penguasaan materi pelajaran) akan berbeda sesuai dengan tingkat kemampuan akademiknya. Hal ini dikarenakan hasil belajar siswa berhubungan dengan kemampuan siswa dalam mencari, mempelajari dan memahami materi pelajaran.

Berdasarkan hasil uji normalitas skor $N$ Gain diperoleh nilai Asymp. Sig (2-tailed) N-Gain pada kelas eksperimen sebesar 0,502 sedangkan nilai Asymp. Sig (2-tailed) N-Gain pada kelas kontrol sebesar 0,382 , dimana nilai Asymp. Sig (2-tailed) N-Gain pada kelas eksperimen dan kelas kontrol lebih dari 0,05 sehingga dapat disimpulkan bahwa data $N$-Gain pada kelas eksperimen dan kelas kontrol berdistribusi normal. Kemudian berdasarkan hasil uji homogenitas diperoleh nilai signifikasi Sebesar 0,362, karena signifikasi lebih dari 0,05 maka dapat disimpulkan bahwa kedua kelompok data (data kelas eksperimen dan kelas kontrol) mempunyai varian yang sama.

Berdasarkan hasil uji Independent Sample T-Test diperoleh nilai sig. sebesar $0,000(0,000<$ 0,05) maka $\mathrm{H}_{0}$ ditolak dan $\mathrm{H}_{1}$ diterima. 
Berdasarkan hasil pengujian tersebut, maka dapat disimpulkan bahwa terdapat perbedaan terhadap keterampilan argumentasi siswa berkemampuanakademik tinggi dan rendah setelah diterapkan model pembelajaran ADI.

Strategi pembelajaran ADI didasarkan pada teori classical conditioning yang dikembangkan Ivan Pavlov, yang menyebutkan bahwa belajar adalah suatu proses perubahan yang terjadi karena adanya syarat-syarat (conditions) yang kemudian menimbulkan reaksi (response). Belajar yang terpenting menurut teori conditioning ialah adanya latihan-latihan yang kontinu. Latihan-latihan atau perlakuan yang dilakukan secara terus-menerus akan berdampak pada hasil belajar yang kehendaki (Pavlov, 1928).

Pembelajaran ADI juga didasarkan pada teori belajar bermakna Ausubel menyatakan bahwa pembelajaran bermakna diawali dengan pengamatan. Dalam belajar bermakna, seseorang harus menghubungkan pengetahuan baru pada konsep yang relevan dengan apa yang telah mereka ketahui, dengan kata lain bahwa pengetahuan baru harus berinteraksi dengan struktur kognitif pembelajar (Ausubel \& Fitzgerald,1961).

Model pembelajaran ADI menurut Andriani (2015) dipandang dapat memfasilitasi siswa untuk memahami

konsep IPA secara baik, karena kegiatan pembelajaran pada model ADI menekankan pada kontruksi dan validasi pengetahuan melalui kegiatan penyelidikan. Model ini dirancang untuk membuat sebuah kelas yang dapat membantu siswa untuk mengerti tentang bagaimana cara membuat sebuah penjelasan ilmiah menggunakan data untuk menjawab pertanyaan ilmiah dan pada akhirnya dapat merefleksikan hasil kerja yang telah dilakukannya. Siswa dapat menguasai konsep lebih baik dengan terlibat pada sesi argumentasi dalam model ADI, karena untuk membangun argumen yang baik siswa membutuhkan penguasaan pengetahuan tentang konten materi yang baik pula.

Penggunaan model ADI dapat meningkatkan keterampilan argumentasi siswa didukung dengan penelitian yang dilakukan oleh Kurniasari \& Woro (2017:173) yang menyatakan bahwa kemampuan argumentasi ilmiah siswa sebelum dan sesudah diberikan pembelajaran mengalami peningkatan. Hal ini juga sejalan dengan penelitian yang dilakukan oleh Sampson dkk., (2011) yang menyatakan bahwa penggunaan model ADI meningkatkan kemampuan siswa dalam berargumentasi, yaitu dengan mempengaruhi cara siswa berpartisipasi dalam argumentasi ilmiah, siswa menjadi lebih disiplin dan menghasilkan kualitas argumen yang lebih baik terutama dalam argumen tertulis yang disusunnya.

\section{KESIMPULAN}

Berdasarkan hasil penelitian dari pembahasan yang telah dilakukan, maka dapat disimpulkan bahwa model pembelajaran Argument Driven Inquiry (ADI) secara signifikan berpengaruh terhadap keterampilan argumentasi siswa berkemampuan akademik tinggi dan rendah.

Berdasarkan kesimpulan diatas, maka saran yang dapat disampaikan adalah: 
1. Apabila guru dan calon ingin meningkatkan keterampilan argumentasi siswa maka dapat menggunakan model Argument Driven Inquiry (ADI) dalam melaksanakan pembelajaran IPA di kelas.

2. Apabila guru dan calon guru ingin menggunakan model ADI, sebelum melakukan pembelajaran hendaknya memberikan penjelasan mengenai setiap tahap-tahap model ADI disertai alokasi waktu yang diberikan, agar setiap tahap terlaksana dengan baik.

3. Sintaks pembelajaran Argument Driven Inquiry (ADI) termasuk panjang daripada model pembelajaran lain, sehingga perlu membatasi waktu pada setiap tahapnya agar semua sintaks pembelajaran bisa berjalan maksimal.

\section{DAFTAR PUSTAKA}

Andriani, Y. dan Riandi. (2015). Peningkatan Penguasaan Konsep Siswa Melalui Pembelajaran Argument Driven Inquiry pada Pembelajaran IPA Terpadu Di SMP Kelas VII. Research Artikel EDUSAINS, 7 (2), 114-120.

Arikunto, Suharsimi. (2012). Dasar-Dasar Evaluasi Pendidikan Edisi Revisi. Jakarta: Bumi Aksara.

Ausubel, D.P., \& Fitzgerald, D. (1961). The Role of Discriminability in Meaningful Learning and Retention. Journal of Educational Psychology, 52 (5), 266274.

Demircioglu, Tuba., \& Ucar, Sedat. 2015. Investigating the Effect of ArgumentDriven Inquiry in Laboratory
Instruction. Educational Sciences: Theory \& Practice, 15 (1), 267-283.

Duschl, R. A., Schweingruber, H. A. dan Shouse, W. A. (2007) Taking Science to School: Learning and Teaching Science in Grades K-8. Washington: National Academic Press..

Hasnunidah, Neni. (2016). Pengaruh Argument Driven Inquiry dengan Scaffolding terhadap Keterampilan Argumentasi dan Keterampilan Berpikir Kritis dan Pemahaman Konsep Biologi Dasar Mahasiswa Jurusan Pendidikan MIPA Universitas Lampung. [Diadopsi dari Disertasi]. Univesitas Negeri Malang.

Kementrian Pendidikan dan Kebudayaan. (2013). Peraturan Menteri Pendidikan dan Kebudayaan Republik Indonesia Nomor 65 Tahun 2013 Tentang Standar Proses Pendidikan Dasar dan Menengah. Jakarta: Kemendikbud.

Kurniasari, Ika Sakti \& Woro Setyarsih. (2017). Penerapan Model Pembelajaran Argument Driven Inquiry (ADI) untuk Melatihkan Kemampuan Argumentasi Ilmiah Siswa pada Materi Usaha dan Energi. Jurnal Inovasi Pendidikan Fisika (JIPF), 2 (3), 171-174.

Osborne, J., Erduran, dan Simon. (2004). Enhancing the Quality of Argumentation in School Science. Journal of Research in Science Teaching, 41(10), 994-1020.

Pavlov, I. P. (1928). Lectures on conditioned reflexes: Twenty-five years of objective study of the higher nervous activity (behaviour) of animals (W. H. Gantt, Trans.). New York, NY, US: Liverwright Publishing Corporation.

Sampson, V., Grooms, J., \& Walker, J. P. (2009). Argument-Driven Inquiry a way to promote learning during laboratory activities: An exploratory study. Science Education, 95(2), 42-45.

Trilling, Bernie and Fadel, Charles. (2009). 21st Century Skills: Learning for Life in Our Times. San Fransisco: Josey-Bass. 
Jurnal IImu Fisika dan Pembelajarannya (JIFP), Vol. 2, No.2, Desember 2018, 53-61

Winarni. (2006). Pengaruh Strategi

Pembelajaran terhadap Pemahaman

Konsep IPA-Biologi, Kemampuan Berpikir

Kritis, dan Sikap IImiah Siswa Kelas VIII

SMP dengan Tingkat Kemampuan

Akademik Berbeda di Kota Bengkulu.

Universitas Negeri Malang, Malang.

Diakses pada tanggal 11 November 2017. 